\title{
MEMÓRIAS DE MULHERES POLICIAIS DA PRIMEIRA TURMA DE FORMAÇÃO DE SOLDADO DA POLÍ́CIA MILITAR DO ESTADO DO RIO DE JANEIRO.
}

\author{
Maicon da Silva Moreira ${ }^{*}$ \& Patrícia Constantino ${ }^{2}$
}

\section{RESUMO}

MOREIRA, M. S.; CONSTANTINO, P. Memórias de mulheres policiais da primeira turma de formação de soldado da polícia Militar do Estado do Rio de Janeiro. Perspectivas Online: Humanas \& Sociais Aplicadas, v. 8, n.22, p.52-69, 2018.

Este trabalho consite em uma pesquisa cujo objetivo foi analisar as memórias de mulheres policiais militares do Estado do Rio de Janeiro, a fim de identificar relatos de assédio moral e sexual vivenciados dentro da corporação militar durante o período de inserção feminina na PMERJ, durante a década de 1980. Foi empregado o método qualitativo de Histórias de Vida Temáticas de três ex-policiais militares. Concluímos que as mulheres policiais militares que ingressaram na corporação na década de 1980 sofreram assédio moral e sexual ao longo de suas experiências na academia militar e na prática profissional. $\mathrm{O}$ método de enfrantamento empregado pelas ex-policiais para suportar as experiências foi o silêncio, em virtude do medo de perder o emprego e por interpretarem que não seriam ouvidas pela liderança da corporação na época. Além disso, a entrada das mulheres a corporação foi desafiadora e complexa não só para as mulheres, mas também para os militares homens que até então trabalhavam em um ambiente profissional masculinizado.

Palavras-chave: Memória Social; Mulheres Policiais; Assédio Sexual; Assédio Moral; 


\begin{abstract}
This work consists in a research which goal was to analyze memories of policewomen of the state of Rio de Janeiro, in order to identify moral and sexual harassments lived inside the military corporation during the period of feminine insertion on PMERJ, during the decade of 1980. It was used the qualitative method of Thematic Life Histories of three exmilitary policewomen. We concluded that the military policewomen that joined the corporation in the decade of 1980 suffered

experiences at the academy and their professional practice. The method of standing up put by ex-policewomen to stand the experiences was the silence, due to the fear of losing their job and understanding that they wouldn't be listened by the corporation leadership at that time. Furthermore, the entrance of women in the corporation was challenging and complex not just for the women, but also for the military men that until then worked in a mannish work environment.
\end{abstract} moral and sexual harassment during their

Keywords: Social Memories; Police Women; Sexual Harassments; Moral Harassments;

\footnotetext{
${ }^{1}$ Universidade Federal Rural do Rio de Janeiro - UFRRJ - Rodovia 465, km 07, s/n - Zona Rural, Seropédica RJ, 23890-000.

${ }^{2}$ Institutos Superiores de Ensino do CENSA - ISECENSA - Laboratório Violência e Instituições - Rua Salvador Correa, 139, Centro, Campos dos Goytacazes, RJ, CEP: 28035-310 /Escola Nacional de Saúde Pública Sergio Arouca - ENSP//FIOCRUZ - Rua Leopoldo Bulhões, 1480 - Manguinhos, Rio de Janeiro - RJ, 21041-210.

(*) e-mail: maicon_moreira@outlook.com

Data de recebimento: 22/11/2017. Aceito para publicação:16/10/2018
} 


\section{PERSPECTIVASCONine CIÊNCIAS HUMANAS E SOCIAIS APLICADAS}

\section{INTRODUÇÃO}

Este trabalho consiste em uma pesquisa sobre as memórias de mulheres que fizeram parte da primeira turma do curso de formação de soldados da Polícia Militar do Estado do Rio de Janeiro (PMERJ), na década de 1980, com o objetivo de identificar relatos de violência praticada através de assédio moral e sexual sofridos dentro da corporação. $O$ intuito da pesquisa não foi apontar possíveis falhas existentes dentro da organização militar, mas sim compreender experiências subjetivas de mulheres dentro de ambientes corporativos marcados maciçamente pela presença masculina.

O debate acerca do trabalho das mulheres nos serviços de segurança pública é um fenômeno recente dentro das universidades. Por este motivo, há grande dificuldade de se encontrar material científico que versa sobre a mulher nas corporações militares. Segundo Calazans (2004), foi a partir da década de 1990, em virtude de uma crise na segurança pública que a discussão sobre o tema entrou para as Universidades.

No ano de 2015 foi divulgada uma pesquisa realizada pelo Núcleo de Estudos de Organizações e Pessoas (NEOP/FGV) e pelo Fórum Brasileiro de Segurança Pública (FBSP) que apontou que $39,2 \%$ das mulheres militares que participaram da pesquisa declararam ter sofrido assédio moral/sexual dentro de suas corporações (FGV, 2015). Este é um dado bastante atual e relevante e serve para fazer pensar sobre as dinâmicas do trabalho dos profissionais de segurança pública, sobretudo as mulheres. Nesse sentido, justifica-se nosso interesse de compreender as dimensões psicossociais da violência psicológica contra mulheres dentro do ambiente de trabalho militar.

A inserção das mulheres no contingente policial, suas experiências e especificidades, são um tema que ainda carece de atenção de pesquisadores, sobretudo da Psicologia, tendo em vista a contribuição que esta ciência pode oferecer para a produção de conhecimento, enriquecendo o debate cientifico acerca das particularidades que envolvem o mundo do trabalho na área de segurança pública. Além disso, a ciência psicológica durante muito tempo se preocupou com o aspecto individualizado do conhecimento produzido na área, deixando de lado as reflexões sobre o aspecto social e a construção de subjetividades em decorrência dele, questão hoje menos problemática em decorrência do fortalecimento da Psicologia Social enquanto disciplina nos cursos de graduação no país.

A polícia militar brasileira nasceu inspirada nas corporações europeias e teve como preceito para sua criação a ideia de que a "segurança pública" é um serviço essencial do Estado. Seu início data de 1808, com a chegada da corte portuguesa ao Brasil, quando o príncipe regente Dom João reproduziu a experiência do policiamento praticado em Lisboa que era baseado no modelo Francês (MINAYO, 2008). A polícia criada pelo príncipe tinha como objetivo auxiliar a Corte e afastar o povo dos ideais liberais advindas da Revolução Francesa, sendo assim motivada pelo intuito de garantir o poder do Estado Absolutista Português, ao invés de efetivamente trabalhar em prol da segurança social (MINAYO, 2008).

Desde a criação da Polícia Militar, muitas transformações ocorrem em sua estrutura. Por exemplo, a organização responsável pela segurança social antes da Polícia Militar era a Guarda Municipal Permanente, que somente a partir de 1866, passa a ser conhecida de fato como Polícia Militar (MINAYO, 2008). Segundo Minayo (2008, p.45): “... com exceção do breve lapso ocorrido em 1831, quando Feijó extinguiu a Divisão Militar da Guarda Real, a 
Polícia Militar tem estado presente na história do Brasil e do Estado do Rio de Janeiro desde 1808.".

A violência e a corrupção policial, temas muito discutidos atualmente, não são problemas atuais, mas sim, históricos. Tais fatos acompanham a história da polícia militar desde sua fundação, quando havia recrutamento forçado de pessoas para compor o quadro de colaboradores, propiciando uma contradição inexorável nas práticas da corporação, pois, se de um lado a corporação tinha como responsabilidade o controle social, os participantes recrutados para tais atividades faziam parte justamente da classe que devia ser controlada pelo Estado: a parcela pobre da população. Também contavam com oficiais que atuavam segundo interesses das pessoas ricas e poderosas da época. Apesar disso, cabe ressaltar que essa característica popular na formação da polícia brasileira não foi aspecto singular do país, isso ocorreu nas corporações policiais do mundo inteiro (MINAYO, 2008).

No Brasil, o ingresso das mulheres nas polícias teve início na década de 1955, no Estado de São Paulo (CALAZANS, 2004; SOARES, 2005). Entretanto, foi somente a partir da década de 1980, que ocorre a concentração de mulheres no universo policial, sendo este mesmo período o momento em que as primeiras mulheres entraram para a Polícia Militar no Estado do Rio de Janeiro (BEZERRA, 2013; SOARES, 2005).

A admissão da mulher no policiamento no Brasil se deu de maneira tímida, pois segundo Calazans (2004), a filosofia tradicional do policiamento é movida pelo poder bélico do Exercito Nacional e por ideologias machistas. Todavia, apesar das limitações no número do efetivo feminino no policiamento, as mulheres já estão presentes nos vinte e seis Estados brasileiros e no Distrito Federal, o que também justifica a importância de compreender o processo de inserção das mulheres no universo corporativo militar e suas experiências.

Bezerra (2013) menciona que a inserção da mulher na polícia militar não foi devido à demanda social, mas porque a organização desejava humanizar a imagem da polícia. $\mathrm{O}$ objetivo da instituição era maquiar a imagem negativa que a organização tinha em decorrência do período histórico, ou seja, a ditadura militar e, portanto, as mulheres representariam uma imagem mais "suave" da instituição, sem, no entanto, alterar suas estruturas. Soares e Musumeci (2005) também apresentam a ausência de mudanças para a inserção das mulheres na corporação militar. A entrada da mulher na polícia não ocorreu a fim de alterar a cultura masculinizada da instituição; ou seja, mesmo após o início de um efetivo feminino na Polícia Militar, ela permaneceu com padrão hierarquizado, disciplinar e machista. Além disso, as funções desempenhadas pelas mulheres policiais eram inicialmente mais voltadas para atividades internas e burocráticas, o que nos permite pensar que tal fato reforçava $o$ estereótipo de sexo frágil dentro da instituição.

Neste mesmo período, o trabalho do policial militar passava a ser visto de modo mais amplo, identificando a necessidade de se ter uma polícia com valores diferentes dos que existiam até então, em que a valorização se dava a partir dos estereótipos da atividade como sendo somente ocupação masculina, por exigir o emprego de força física no cotidiano de trabalho por exemplo. Após a crise que motivou a corporação maquiar a imagem dela própria, ela passou a valorizar competências que requerem inteligência, capacidade para resolver conflitos, inovação, trabalho em equipe e isso pode ter motivado a entrada das PMFEM (PMFEM - É a sigla utilizada para identificação das policiais femininas dentro da Polícia Militar. Conforme compartilhado pelas interpretes, os policiais masculinos eram conhecidos como PM e elas como PMFEM. Neste artigo quando nos citarmos a sigla PM estaremos nos 
referindo aos policiais militares do sexo masculino.) (CALAZANS, 2004, p. 144).

Em relação à definição de violência, segundo Njaine (2013) ela foge a qualquer conceituação precisa e cabal, sendo assim, existem muitas definições, pois ela é um fenômeno complexo e multicausal. Além disso, é também um fator humano, social e histórico, presente em quase todas as sociedades, que abrange todas as classes e segmentos sociais e que faz parte de nós enquanto seres humanos e pode aumentar ou diminuir em decorrência de uma série de fatores. A violência também é compreendida quanto a sua natureza, podendo ser física, psicológica, sexual envolvendo negligência, abandono ou privação de cuidados (NJAINE, 2013,).

Esta pesquisa enfatiza os tipos de violência psicológica e sexual concebida através de comportamentos de assédio moral e sexual. Segundo Njaine, violência psicológica é compreendida como: “... agressões verbais ou gestuais com o objetivo de aterrorizar, rejeitar, humilhar a vítima, restringir-lhe a liberdade ou, ainda, isolá-la do convívio social. Indica também a rejeição de pessoas, na inter-relação" e a violência sexual seria: “... ato ou ao jogo que ocorre nas relações hétero ou homossexuais e visa estimular a vítima ou utilizá-la para obter excitação sexual nas práticas eróticas, pornográficas e sexuais impostas por meio de aliciamento, violência física ou ameaças" (NJAINE, 2013, p.39).

Conforme Heloani (2004, p. 2), “a discussão sobre assédio moral é nova, mas o fenômeno é velho". Ou seja, apesar de o fenômeno em si acontecer no contexto organizacional faz bastante tempo, só recentemente que o mesmo passou a ser explorado e discutido. Avila $(2008$, p. 1) diz que em razão dos desgastes que provoca, dos impactos negativos que causa à saúde e ao bem-estar da vítima no trabalho, o tema assédio moral se tornou uma forte preocupação social, além de ser fenômeno estudado por diversos segmentos, a saber: medicina, psicologia, administração, sindicatos, etc.

Quanto ao referencial teórico, utilizamos nesta pesquisa o conceito de memória social em uma perspectiva psicossocial. Inicialmente, a memória social foi formulada por Maurice Halbwachs (1877-1945), sociólogo francês, que seguia a tradição durkheimiana, morto em 1945, em um campo de concentração nazista na Alemanha. Halbwachs compreendia que a memória era um atributo coletivo, ou seja, refutava a ideia de uma memória como característica da cognição individual. Para Halbwachs, as memórias são coletivas e não nos lembramos sozinhos, mas sim, são as outras pessoas que nos fazem recordar (HALBWACHS, 2006).

As lembranças em Halbwachs são grupais porque tudo o que é vivenciado, na verdade, é compartilhado socialmente; logo, são memórias sociais. $\mathrm{O}$ autor enfatiza o predomínio do social sobre o indivíduo, entendendo assim que a formação das memórias é sujeita ao que é compartilhado no contexto social em que o indivíduo é exposto. Por isso, a memória é elaborada no grupo, mas necessariamente não é preciso que o grupo esteja presente para que ela seja rememorada, pois sempre levamos conosco parte do que foi vivido através de nossa memória que é coletiva (HALBWACHS, 2006, p. 30).

A concepção de memória por Halbwachs é feita a partir dos quadros sociais da memória. Segundo Bosi (1994, p. 54) "A memória do indivíduo depende do seu relacionamento com a família, com a classe social, com a escola, com a igreja, com a profissão; enfim com os grupos de convívio e os grupos de referência peculiares a esse indivíduo". Portanto, nosso estudo se pauta nas memórias profissionais de mulheres da área 
de segurança pública e baseados na concepção de Halbwachs, o conteúdo mnêmico rememorado pelas interpretes não é fragmento somente da memória individual, mas sim, do grupo a que elas fizeram parte.

Outro estudioso do conceito de Memória Social foi o psicólogo inglês Frederic Bartlett (1886-1969), que inaugurou a perspectiva psicossocial da memória, pois a compreendia como atributo do sujeito em interação (SANTOS, 2003). Para Bartlett, a memória é tanto social quanto subjetiva, à medida que nossas recordações estão relacionadas diretamente com a importância social que a lembrança possui e também o modo da recordação que é um movimento subjetivo e representa o como se lembra (BOSI, 1994). Em Bartlett, a percepção é entendida como parte do processo de rememoração, pois só armazenamos aquilo que possui significado para nós, pois antes de nos recordarmos percebemos. Por isso, diferentemente de Halbwachs, Bartlett reconhece a importância do aspecto subjetivo no processo de lembrar, apesar de compreender a existência de esquemas que são previamente internalizados através dos processos de socialização (SANTOS, 2003).

Celso Sá (1941-2016), psicólogo social brasileiro, também explorou as conceituações acerca da teoria de memória social no âmbito da psicologia social e, apesar de estabelecer princípios unificadores na literatura sobre a participação subjetiva dos sujeitos no processo de lembrar, compreende que o conceito em si é amplo, portanto não pode ser interpretado de forma taxionômica (SÁ, 2005). O autor definiu seis concepções sobre memória e dentre elas citou a "Memória Social/Coletiva" como sendo basicamente, a termo, as ideias de Halbwachs.

Neste sentido, esta pesquisa objetiva identificar práticas consideradas como assédio moral e sexual na visão das ex-policiais entrevistadas, compreender a história da inserção dessas intérpretes por meio das narrativas mnêmicas e identificar as estratégias que as mulheres de enfrentamento que elas traçaram para suportarem as experiências violentas.

\section{METODOLOGIA}

O método de pesquisa empregado foram as "Histórias de Vida", pois através das memórias das intérpretes podemos compreender suas experiências profissionais e a realidade vivenciada no processo de inserção das mulheres na Polícia Militar no Estado do Rio de Janeiro. Tal método possui natureza qualitativa e foi inicialmente desenvolvido pela Escola de Chicago, nos EUA (SANTOS, 2003; TINOCO, 2004).

As Histórias de vida possibilitam perceber detalhes subjetivos sobre as entrevistadas, e também compreender regras e funcionamento do grupo social a que elas fazem parte (TINOCO, 2004). Além disso, conforme menciona Queiroz (1988), o interesse do pesquisador está em apreender conteúdos para além daqueles trazidos pelo entrevistado na narrativa, ou seja, é o que se insere nas coletividades. Por isso, nos atentamos com o conteúdo trazido pelos intérpretes, mas analisamos a relação das narrativas pessoais com o contexto a que estavam inseridas.

Em nossa pesquisa também nos apropriamos daquilo que TINOCO (2004) chama de História de Vida temática, uma vez que nosso objetivo não foi extrair das intérpretes detalhes sobre todos os campos da sua vida, mas sim, nos atermos as suas experiências profissionais. Através disso, conseguimos nos manter focados em nosso objeto, que era compreender as memórias de mulheres policiais a fim de identificar relatos de violências.

A análise teórica se fundamentou nos estudos de memória social. Portanto, todo o 
material construído com a ajuda das interpretes foi analisado, tendo como base o pressuposto de que não há separação entre indivíduo e sociedade, mas sim, uma interligação na fala do sujeito que circunscreve aquilo que é vivido no coletivo.

Participaram da pesquisa três mulheres ex-policiais militares que fizeram parte da primeira turma feminina de formação de soldados da polícia militar, do Estado do Rio de Janeiro, ocorrida em 1982. Para evitarmos a identificação individual das participantes utilizamos pseudônimos e assim as chamamos de Maria, Claudiana e Gisele. Também não mencionaremos a patente de nenhuma delas ao longo do artigo.

Todas as participantes citadas acima têm entre cinquenta e sessenta anos de idade e trabalharam nos batalhões localizados na cidade do Rio de Janeiro. Quanto ao nível de instrução, duas possuem ensino superior completo e uma, ensino superior incompleto. Sobre as que concluíram a faculdade, uma cursou fora da instituição militar, ou seja, em uma universidade externa, e outra cursou dentro da corporação como parte do processo de promoção. Dentre as três participantes, duas delas (Maria e Gisele) estão na reserva (ou seja, se aposentaram) e uma (Cladiana) se desligou da corporação por motivos pessoais três anos após o início das atividades.

Para recrutamento das participantes, foi empregada a técnica conhecida como "bola de neve" ou "snowball", a qual se utiliza de um primeiro entrevistado, chamado de semente, e após sua participação, ele auxilia o pesquisador a localizar os demais participantes no perfil desejado para a pesquisa (VINUTO, 2014). A primeira entrevistada foi localizada a partir de indicação de uma pessoa conhecida do primeiro autor e através da primeira, as outras duas foram localizadas. O meio utilizado para comunicação com as participantes foi o telefone e as redes sociais.

Ressaltamos que o contato com as intérpretes antes das entrevistas foi de total importância para criação de vínculo entre elas e o pesquisador, pois foi justamente o vínculo que possibilitou que elas se sentissem à vontade e dispostas a participarem do estudo. A proximidade resultante desse contato prévio contribuiu para que intérprete e pesquisador pudessem aproveitar o momento da transformação das lembranças em conteúdos da uma memória social (BOSI, 2003). Além disso, as intérpretes compartilharam detalhes de suas vidas e também trabalharam em prol desta pesquisa; portanto, são os personagens centrais na construção de todo o material produzido neste artigo. Segundo Bosi (1994, p.55): "lembrar não é reviver, mas refazer, reconstruir, repensar, com imagens e ideias de hoje, as experiências do passado. A memória não é sonho, é trabalho".

As entrevistas com as três intérpretes se deram da seguinte forma: A primeira interprete, Maria, participou de duas entrevistas, sendo a primeira através do Skype e a segunda presencialmente. A segunda interprete, Claudiana, participou apenas uma vez e através do Skype. A terceira interprete, Gisele, participou apenas uma vez e presencialmente.

Utilizou-se entrevistas não estruturadas, com o objetivo de deixar as intérpretes à vontade no momento da rememoração. Porém, foi construído um roteiro com 18 perguntas a serem utilizadas somente caso elas não mencionassem tais conteúdos em suas narrativas. Apenas algumas dessas perguntas foram utilizadas ao longo das entrevistas, pois as narrativas se deram de forma livre: as intérpretes foram se recordando dos acontecimentos e narrando sem interrupção. O entrevistador realizou intervenções somente para ampliar as imagens evocadas por elas, objetivando compreender os temas que surgiam das lembranças. 
As três entrevistas foram gravadas com autorização das participantes e com ajuda de um gravador de áudio e transcritas para realização da análise. Todas as interpretes leram o conteúdo transcrito antes de redigirmos este artigo com apresentação dos resultados. Os arquivos de transcrição foram lidos diversas vezes, a fim de identificarmos as saturações que seriam repetições de ideias e opiniões dos entrevistados (TINOCO, 2004). Após análise, identificamos as seguintes categorias: a) $\mathrm{O}$ inicio na corporação, b) visão romantizada sobre o que era ser Policial Militar, c) período histórico, d) Assédio Moral e Sexual e e) o primeiro desfile de 7 de Setembro com a participação das policiais mulheres.

O projeto desta pesquisa foi submetido ao Comitê de Ética em Pesquisa - CEP - da plataforma Brasil, em 22 de março de 2017, sendo aprovado em 10 de maio de 2017 e recebendo o seguinte número de protocolo: 2.056.912.

\section{RESULTADOS E DISCUSSÃO}

Adiante, apresentamos os conteúdos extraídos das entrevistas realizadas neste estudo. As três ex-policiais são consideradas nesta pesquisa como intérpretes, pois foram as responsáveis por destrinchar os detalhes sobre as experiências das mulheres na primeira turma de formação de soldados da Polícia Militar do Estado do Rio de Janeiro. As lembranças aqui transcritas são conteúdos subjetivos, portanto, expressam fragmentos do passado em movimento e não estático e linear. Segundo Halbwachs (2006), a memória é viva, e também está em constante construção e movimento.

Percebemos nas falas das intérpretes que as lembranças sempre estavam acompanhadas de uma terceira pessoa. Ou seja, o conteúdo rememorado foi narrado, na maioria das vezes, no plural, como se as intérpretes estivessem buscando nas experiências passadas ajuda de outros personagens para costurar suas lembranças. Os conteúdos rememorados foram trazidos à consciência como se, de fato, em todo o momento as mulheres não estivessem sozinhas em suas lembranças e experiências, pois junto delas estavam suas colegas de curso e também os demais policiais homens. Segundo Halbwachs, "não é o indivíduo em si ou alguma entidade social que recorda, mas ninguém pode lembrar realmente a não ser em sociedade (HALBWACHS, 2006, p. 23)".

\section{a) O início na PMERJ.}

Identificamos que o início na corporação foi marcado para as PMFEM pelo medo da expulsão no curso e por um sentimento de proteção por parte dos policiais masculinos e da própria corporação em si. Além disso, cabe sinalizar que as atividades desempenhadas pelas PMFEM inicialmente eram mais voltadas para questões sociais, o que, de fato, coincide com os dados levantados por SOARES (2005) sobre a falta de estrutura modificada para receber o efetivo feminino. Portanto, a maioria das PMFEM foi designada para o controle de trânsito, hospitais, revistar mulheres e para atuação comunitária, especialmente em locais de movimento turístico: "A missão das mulheres policiais seria, assim, funcionar como uma espécie de cartão de visita, como elemento de marketing, e sua incorporação visaria uma reforma cosmética, que, sem alterar paradigmas, sinalizasse mudança e modernização" (SOARES, 2005, p. 18).

Eu como trabalhava na Zona Sul era uma coisa assim de tirar foto com os gringos que queriam tirar fotos. "Nossa, é uma mulher militar!" Era uma coisa mais social, fazíamos um trabalho mais social ali. (Maria) 
As intérpretes relatavam muito medo, em virtude de as PMFEM estarem em processo de avaliação no decorrer dos 6 meses de curso de formação. A capacitação para formação de soldado policial militar no Rio de Janeiro iniciou no mês de março de 1982 e findou em setembro do mesmo ano, admitindo no final 150 mulheres. O período de capacitação ocorrido no Centro de Formação e Aperfeiçoamento de Praças (CFAP) localizado em Sulacap, bairro da zona norte da cidade do Rio de Janeiro, foi liderado por policiais masculinos, tendo em vista de que se tratava da primeira turma de formação de policiais femininas (PMFEM) (SOARES, 2005). Conforme pudemos identificar nas falas das intérpretes, a experiência foi marcada de forma muito negativa por conta da cobrança imposta.

O medo de ser punida e ser excluída do curso era maior que qualquer coisa. Por isso, não me chocava, apenas seguia as regras. (...) Poderíamos ser expulsas se assim quisessem, sem problemas. Na época, não tinha essa democracia de entrar na justiça. (...) Eles eram horríveis com a gente, dizendo que não podia engravidar, porque se engravidássemos o que acontecia era que a gente era excluída do curso sem direito a nada. Não podia ficar grávida e todo mês tinha que fazer exame de urina durante o curso para dar a certeza que estava legal. Na época, com 22 anos, eu era virgem e não tinha me casado, eu fazia xixi para todo mundo. (Maria)

Assim que eu entrei foi o momento mais difícil pra mim. O desafio foi de conseguir permanecer lá porque qualquer coisa que fazíamos podia ser motivo pra sairmos. $\mathrm{O}$ nosso desafio era conseguir permanecer, conseguir um plano de cargos melhor. Permanecer, ser respeitada e dar tudo certo". (Claudiana)

Eu lembro que lá no início tinha que fazer exame de urina sempre pra saber se não estava grávida. A gente não podia namorar com ninguém lá de dentro. (Gisele)

Sobre o sentimento de proteção, este se refere às atitudes dos colegas PM e às estratégias tomadas pela corporação para receber e evitar qualquer tipo de problema, tendo em vista que a organização militar até aquela época era um ambiente profissional exclusivamente masculino. A primeira turma de formação em soldados teve somente instrutores homens, pois na época não existiam mulheres na corporação. Além disso, inicialmente, a proteção das primeiras mulheres durante o curso fez com que houvesse separação entre os PM e as PMFEM. Por isso, na presença delas todos os soldados e oficiais tinham que ficar virados de costas, exceto os oficiais responsáveis pela capacitação (SOARES, 2005).

Era a primeira turma, então era uma questão política do governo. Era tudo novo, então tínhamos que ser selecionadas da melhor forma. Sem estresse sem nada porque não tinha essa maldade de hoje. (...) Na época, a gente foi separada dos homens no curso. Nosso curso no CFAP a gente não via homem e eles ficavam de costas em torno porque dentro do CFAP tem os policiais internos, os que ficam tomando conta dos limites lá, e eles ficavam de costas para não olhar. A gente não tinha nenhum acesso a homens, só os oficiais que faziam as nossas instruções e o coronel que iam fazer as palestras, as aulas, tudo eram oficiais e alguns sargentos auxiliares/monitores. A gente não tinha colega homem, não existia a possibilidade, não podia ter relacionamento nenhum. (Maria)

Então, a gente também foi muito privilegiada porque como era a primeira turma, nós fomos muito paparicadas. Ninguém podia chegar perto. Os homens não podiam falar com a gente. Nem a guarda podia falar com a gente, então quem chegasse perto da gente ficava preso. (Gisele)

Devido ao fato de as intérpretes terem participado da primeira turma de formação, suas experiências serviram como modelo para o papel feminino dentro da polícia militar, pois em muitos momentos, as entrevistas mencionaram que atualmente as PMFEM não passam pelas 
mesmas experiências que elas. Além disso, acreditamos que as primeiras experiência das mulheres na PMERJ serviram como aprendizado não somente para as iniciantes na profissão, mas sobretudo para os homens policiais praças e oficiais que formavam a corporação na época e tiveram que se adaptar a uma nova realidade em seu ambiente de trabalho, como mostra os relatos abaixo:

Nós mulheres éramos o foco do momento. (...) Era uma experiência pra gente, mas também pra eles. (Claudiana)

Aqui só tem policiais de barra pesada que vão pro confronto, vão pro confronto mesmo, é matar ou morrer e eu não sei o que eu vou fazer com vocês." (Gisele)

\section{b) Visão romantizada sobre o que era ser Policial Militar.}

As PMFEM entrevistadas compartilharam o que pudemos compreender como uma visão romantizada sobre o que era ser policial militar e isso implicou, em alguns casos, no sentimento de decepção com a profissão. As experiências subjetivas das mulheres policiais mostram o desconhecimento delas sobre a carreira militar, assim como sobre o universo policial em si. Por isso, muitas delas alimentavam uma imagem romantizada sobre o papel e atribuição da polícia militar.

Supomos que a falta de conhecimento acerca das atribuições de um polical se deva ao fato de elas terem ingressado muito novas na corporação, pois muitas realizaram a prova de admissão com 19- 20 anos de idade e também porque até aquela época o militarismo era uma profissão apenas para homens. Sendo assim, não havia referências para elas sobre mulheres na Polícia.

Eu tinha 22 anos e naquela época era tudo romântico, era tudo muito lindo. Eu só
queria colocar a minha linda farda e falar que eu era policial. Não tinha essa cultura
de violência de hoje. Então, foi uma coisa muito romantizada e meu pai me fez a
cabeça dizendo que eu ia ficar numa escola, eu ia passar a ser telefonista no quartel e
eu ia usar uma linda farda e pronto, isso me bastava. Nessa época, eu não pensava
em carreira, não pensava em nada. Eu pensava em colocar uma farda e fazer tudo
aquilo que meu pai dizia que seria maravilhoso pra mim. Depois. né, a gente vai
amadurecendo e as coisas vão acontecendo e fica diferente, mas no início foi assim,
muito tranquilo. (...) na inocência e romantismo. Eu não tinha nenhuma referência
de mulheres na polícia, então era tudo lindo. Não tinha como saber. (...) No meu
primeiro dia de trabalho, eu fiquei muito encantada, né, eu me senti assim muito
importante porque as pessoas olhavam pela primeira vez uma mulher policial
armada." (Maria)

Eu acabei me frustrando com a PM porque ficávamos mais em cabina, não era dinâmica como a gente imaginava ser a atividade do policial. Não tinha ação sabe. Se fosse hoje, eu não sei se eu faria o concurso pra PM. Com 19 anos, a gente é muito infantil, muito menina, com muita fantasia. Hoje eu sou uma mulher mais madura, vejo o real perigo que tinha". (Claudiana)

Apesar do sentimento de desilusão, elas encontraram na corporação uma possibilidade de ascensão econômica, podendo, inclusive, ajudar a própria família que era frágil economicamente. Além disto, a afeição adquirida ao longo dos anos trabalhando como policiais, o sentimento para com a instituição migrou de desilusão para gratidão, em virtude da melhoria de vida que a corporação proporcionou. É pertinente frisar também o relato de uma das intérpretes sobre o medo que sentia de não corresponder às expectativas que a sociedade impôs para a mulher ao se inserir na polícia, como se fossem elas a salvação para os problemas da organização. Segundo Lopes, "A experiência de inserir a presença das 
mulheres em atividades de rua gerou um impacto real e simbólico na PMERJ, uma vez que existia uma prática generalizada de extorsão e corrupção policial” (LOPES, 2010, p. 2).

\begin{abstract}
Aí estourou na mídia porque era a primeira turma de mulheres na polícia, mas foi muito bom pra mim, foi uma experiência que eu nunca tinha vivido até então na minha vida. Eu era muito pobre, de subúrbio, uma menina que não tinha nada, passava necessidades. $\mathrm{Na}$ época, era um salário bom, pra uma menina era muito bom. Solteira, jovem, que não tinha nada, vivia de favores de parentes, né, era uma coisa muito boa. Então fiquei deslumbrada com aquele mundo novo que estava se abrindo pra mim. Emprego, dinheiro, eu fiquei deslumbrada. (...) Toda hora era falado que "as mulheres na rua iriam resolver porque as mulheres são menos corruptas, as mulheres são mais eficientes, não se corrompem”, então eu tinha muito medo de falhar de não ser isso que todo mundo esperava. (Gisele)
\end{abstract}

\title{
c) Influências do período histórico.
}

Identificamos a influência do período histórico na experiência da primeira turma de formação de PMFEM, tendo em vista que o país encontrava-se sob o domínio da Ditadura militar. O período do governo militar no Brasil, mais conhecido como "Ditadura Militar", ocorreu entre os anos de 1964 a 1989, e teve seis governos ao todo, incluindo um governo civil (CODATO, 2005). Quanto a isso, podemos compreender o movimento como sendo uma conquista atravessada pela quebra de paradigma e por superação de desafios, pois as mulheres terem ingressado na corporação em meio à Ditadura Militar pode ser considerado um acontecimento importante no âmbito das conquistas femininas.

\footnotetext{
Militar era meio que blindado para essas coisas, a constituição era antiga, só existia para nós os deveres a serem cumpridos, bem maior que os direitos. (...) Hoje em dia tudo você pode ir para a justiça, antigamente você não tinha essa possibilidade, não podia ir pra justiça. Era o militarismo e pronto. A chamada "Rquero" (regulamento policial - regulamento que eu quero). Era assim. (...) A gente vivia em um regime militar, era final da ditadura (...) Vivíamos em um regime militar, ditador e a palavra de uma mulher não significava nada. (Maria)
}

As intérpretes mencionaram o contexto histórico como sendo responsáveis pelo modelo de enfrentamento que elas encontraram para suportar acontecimentos de seu cotidiano. É interessante pensar que a maioria desses comentários não foi esmiuçado, não houve detalhes, apenas a notificação de que tais comportamentos foram aplicados em virtude do contexto histórico. A idade das entrevistadas sugere que elas entraram para a corporação militar no final de sua juventude e início da fase adulta (idade madura) e segundo Bosi (1994), a partir da idade madura, os relatos se caracterizam por uma pobreza dos acontecimentos e estagnação da narrativa. Isso se dá pela precipitação do tempo. O concurso para admissão feminina na polícia militar permitiu o ingresso de jovens entre 18 e 23 anos de idade, solteiras e que não estivessem grávidas (SOARES, 2005).

Uma pressão, uma ultrapassagem de direito, mas era outra lei, era militar. Você não podia questionar nada.(Claudiana)

Nós entramos no final da ditadura, bem finalzinho, mas ainda o militarismo era bem forte ainda.. (Gisele)

\section{d) Assédio Moral e Sexual.}

As narrativas mnêmicas das interpretes que participaram deste estudo evidenciaram também a existência de violências sofridas dentro da corporação militar. De acordo com o contexto compreendido nos conteúdos das entrevistas, tais práticas se deram de diversas 
formas e ocorreram isoladamente; ou seja, as entrevistadas não mencionaram suas experiências com a violência como sendo práticas constantes realizadas por um único integrante da corporação, mas sim vivenciadas em situações diferentes e com pessoas diferentes que as fizeram sentir-se violadas de alguma forma.

Os fatos rememorados pelas interpretes não são exclusivos do período do curso de formação. Pelos detalhes das narrativas, eles se assemelham mais às experiências que as entrevistadas tiveram ao longo da trajetória como policiais e, segundo Halbwachs, "são as repercussões, não o acontecimento, que entram na memória de um povo que passa pelo evento (...) Cada grupo totalmente definido tem sua própria memória e uma representação só dele de seu tempo" (HALBWACHS, 2006, p. 130). Diferentemente de Halbwachs, Bartlett reconhece a influência do social no individuo, mas apenas quando há significados, percepção das práticas já estabelecidas para servirem de conteúdo rememorado; por isso, ele trabalhou com a ideia de esquemas, pois eles remetem a passagem de um padrão a outro mediante percepção (SANTOS, 2003). Portanto, os conteúdos trazidos à tona pelas entrevistadas são lembranças que se fixaram, foram percebidas por elas no decorrer da vida profissional, foram correntes de pensamentos que se fortaleceram ao longo do tempo.

Sobre o tipo de violência mais presente na experiência das mulheres que participaram da primeira turma formação de soldado da polícia militar, podemos entender que foi o assédio moral, ou seja, violência psicológica. As ex-policiais relataram frases ditas por antigos líderes que as deixavam tristes e afirmaram existir na corporação muita humilhação por parte dos colegas de profissão (PM). O assédio moral é um comportamento presente nas relações humanas desde os primórdios da civilização e pode ser observado em diversos contextos, desde a família que é o primeiro grupo social humano, até a escola e trabalho, como, por exemplo, as corporações militares (AVILA, 2008).

Então essa coisa foi um grande desafio porque eles não acreditavam na gente. Não acreditavam mesmo, achavam que a gente estava ali pra roubar o emprego deles. Falavam que havia um monte de chefe de casa desempregados e um monte de mulher ali sem fazer nada. (...) Porque o preconceito dentro da corporação era muito grande com os colegas, mas muito grande. (...) A gente sofria preconceito de todos os tipos. (...) Nossa, a gente passou por cada humilhação que você não tem nem ideia. (...) Existia era o famoso "pede para sair". "Não está satisfeita vai embora procurar outro emprego"... "problema é seu". Ninguém acolhia você (...) E diziam que se alguém estivesse grávida que seria expulsa... humilhavam, humilhavam, humilhavam, era muita humilhação. Os coronéis eram muitos rigorosos, eram muito ruins, muito maus mesmos. (...) Mas, sempre tinha aquela coisa de FEM... FEM era a policial feminina. Até hoje eles chamam de FEM. "Que FEM não serve para nada, malditas FEM"... Tudo era maldita. "Bicho maldito" mais ou menos isso. (...) Penso que a maioria sofreu assedio. (Maria)

Quando eu tinha mais ou menos um mês ou dois de curso, eu participei de uma entrevista para o jornal O Globo. Foi traumatizante! Fiquei sofrendo um mês por causa disso, já tinha até cortado o cabelo. O jornal queria fazer uma reportagem pra falar sobre as pioneiras na PM, o que nos motivou a entrar pra PM. A PM passou meu endereço e também passou de mais duas meninas. Eles autorizaram o jornal a me entrevistar na minha casa. Quando eles chegaram eu estava à vontade, estava em casa, tinha 19 anos, então estava de short, peguei minha cachorra coloquei no colo e o fotógrafo bateu uma foto de baixo pra cima, ou seja, apareceu só perna. E meu ingresso já estava marcado, minha incorporação já estava marcada e quase que eu dancei porque o Coronel queria me tirar, porque eu não era digna de entrar pra PM porque eu já tinha posado de short. E eu já com a cabeça quase que raspada, porque eles nos faziam cortar o cabelo igual a homem. Enfim, acabou que teve opinião pública, debate "A Claudiana deve sair por que posou de short?". Acho que 
aconteceu algo semelhante com uma menina na Marinha e a PM quis fazer o mesmo. Eles me pegaram de pato. Só que naquela época não tinha indenização por danos morais e fiquei imensamente agradecida por eles terem me deixado permanecer. Não foi um assédio sexual, mas foi moral e eu e minha família sofremos muito na época. (Claudiana)

A policial feminina ou era muito amada pelos outros policiais, pelos pares e superiores, ou era odiada. Ouvia-se muito a frase "O que essa mulher está fazendo aqui, tinha que procurar um tanque pra lavar roupa”. Mas, lavar roupa no tanque eu nunca ouvi não, mas "O que você está fazendo aqui? Eu não sei o que vocês estão fazendo aqui, porque aqui não é lugar de mulher”. (Gisele)

Ainda sobre o assédio moral vivenciado pelas ex-policiais, apontamos para as experiências narradas, identificando-as como fazendo parte de três fases das cinco fases do Psicoterror definidas por Leymam (2000). Segundo este autor, citado por Avila (2008), a primeira fase refere ao início, quando a situação desencadeante está somente na esfera do conflito. A segunda fase refere-se à hostilização, com o propósito de minimizar a vítima no grupo, diminuí-la psicologicamente. Por fim, a terceira fase se refere ao momento em que a organização e os agentes nela inseridos ficam ciente dos acontecimentos, mas tendem a responsabilizar a vítima e não o agressor (AVILA, 2008).

-“Não interessa seu estado, quem mandou você entrar para a polícia? Quem mandou
você ficar grávida? Eu tinha que me colocar no meu lugar de cabo e ser a última a
almoçar". (...) Isso eu nunca esqueci, ele me humilhou... me humilhou e eu grávida
de sete meses e ninguém podia falar nada. Porque a arbitrariedade comia solto né..."
(Maria)
Não sei se a Maria te contou que uma vez o Comandante colocou todas nós em
forma, 150 mulheres em forma, lá no batalhão no Estácio e ali ele falou: "Eu não
suporto mulheres, eu não suporto vocês, vocês ou estão grávidas ou estão sangrando,
eu odeio vocês". Isso foi uma coisa impactante pra mim. Ele colocou as 156
mulheres em forma porque ele achava que mulher dava muito problema. Por que
mulher tem filho pequeno, menstrua, engravida, aí sai da escala." (Gisele)

Quanto ao assédio sexual, este pode ser posto em prática através de constrangimentos por insinuações constantes, cantadas, com intuito de obter vantagens ou favorecimento sexual. Pode acontecer de forma sutil, velada, através de chantagem ou por meio de promessas (MT, 2013). Segundo Hirigoyen apud Guimarães (2006), as mulheres são mais vitimadas que os homens, assim como passam por assédios com conotações mais sexuais e machistas. Percebemos que as lembranças das ex-policiais nos apresentam experiências de constrangimentos, de abuso de poder e violações explicitas. Muitas experiências rememoradas foram explicadas com teor de indignação, enquanto que outras como fatos vivenciados e que hoje já não possuem nenhuma influência emocional para elas.

Em um serviço de $24 \mathrm{~h}$ no carnaval, por exemplo, eu era oficial de dia e me questionei: "Onde é que eu vou dormir?" Teve um oficial que falou assim: "Ah, você vai dormir junto comigo no meu quarto". Eu falei: "Não". Ele falou: "Você é oficial como eu, qual o problema?" Eu falei: "Não, nenhum problema, eu sou oficial como você, mas eu sou mulher. Sinto muito, mas eu não vou dormir com você". Era assim, era difícil. Eu nunca falei isso para ninguém, mas eu não sei o nome da pessoa, eu não me lembro dele, talvez minha memória não queira lembrar. Uma vez, eu fui à enfermaria porque eu estava chorando, estava sensível e o enfermeiro passou a mão nos meus seios. Foi o que ele fez comigo. Eu pensei "Não estou acreditando nesse filme de terror"! (...) Fui lá para sentar, respirar, encontrar um enfermeiro ou médico para me ajudar. Foi no mesmo dia em que o capitão me humilhou, foi quando eu fui para enfermaria. Não tinha psicólogo, mas tinha um 
enfermeiro e o médico não estava e ele fez isso. Não sei se ele quis dizer: “Ah, se está aqui tem que se submeter a qualquer coisa”. (...) Eu não ia pagar para ver. Uma coisa que não se podia falar era sobre assédio sexual, abuso, preconceito, etc. Se falássemos ou nos queixássemos, a história se voltava contra nós. Não tínhamos voz, apenas devíamos cumprir as ordens e fingir que não estava entendendo algumas investidas. Eu, como disse antes, sofri aquele abuso quando grávida, depois os oficiais (principalmente) faziam de tudo para nos ver trocar de roupa "sem querer"... (...) Eu tive tanto medo e não pensava em assédio na época, achava que o cara era doido, no máximo.” (Maria)

Tinha muito essa coisa de assédio né. Esse cara escancarava porque quando ele me via ele parava, tipo congelava, não era nada verbal, ele ficava me olhando com aquele olhar nojento. Aí eu ficava com muito medo. Eu pensava: "Gente, eu estou aqui no meio desse monte de homens, o que vou fazer?” (...) Lá eu sentia um pouco de medo, como esse medo que a gente sente na rua eu sentia lá dentro porque eram 400 homens pra 4 mulheres. Eu tinha muito medo dele. Quando tínhamos plantão de $24 \mathrm{~h}$, eu deitava no beliche, igual quartel mesmo, eu dormia fardada e com a arma atrás do travesseiro e se eu escutasse um espirro acordava. (...) Eu reclamei, eu disse: "Isso é um assédio, eu estou incomodada e agora eu fui subir a escada e ele me pegou ali no pé da escada, eu falei pra ele sair e ele disse que não ia sair que ia ficar mesmo". Aí ele respondeu: "Também, você com esse cabelão solto, com esse vestidinho, você quer o quê?Eu vou falar com ele, mas também prende esse cabelo". Quer dizer, a culpada era eu. Eu sou a culpada? Ele estava me olhando, me assediando porque eu estava de cabelo solto e de vestido. (...) Fui pedir uma ajuda da liderança: "Fulano, eu voltei do curso e estou sem gratificação, o que você pode fazer pra me ajudar?" Ele bateu a mão no colo dele. Sabe, eu tive que me fazer de desentendida e sair da sala, mas acho que isso acontece em todos os lugares e não é um problema da polícia não.” (Gisele)

\section{e) $O$ primeiro desfile de 7 de Setembro com a participação das policiais mulheres.}

O primeiro desfile das policiais femininas na polícia militar também ficou marcado na experiência das intérpretes, pois as três PMFEM citaram o evento em suas narrativas. Segundo duas das interpretes, Maria e Gisele, o dia 7 de setembro de 1982 foi um dia de revolução para as mulheres na PMERJ: a "Revolução do Sapato". Embora o tema saturado tenha sido o mesmo, os dados lembrados não corresponderam à mesma imagem, pois apesar de a memória ser coletiva é o sujeito quem evoca os conteúdos rememorados.

A força de evocação pode depender do grau de interação que envolve: eventos, de repercussão restrita diferem, em sua memorização, dos que foram revividos por um grupo anos a fio. Mas, uns e outros sofrem de um processo de desfiguração, pois a memória grupal é feita de memórias individuais. Conhecemos a tendência da mente de remodelar toda experiência em categorias nítidas, cheias de sentido e úteis para o presente. Mal termina a percepção, as lembranças já começam a modificá-las: experiências, hábitos, afetos, convenções, vão trabalhar a matéria da memória" (BOSI, 1994, p. 419).

A primeira revolução da mulher dentro da polícia militar foi a revolução do sapato (risos). Sabe que no dia do desfile de 7 de setembro, isso no primeiro ano, todas nós tínhamos que estar calçadas com sapatos fechados igual sapato de homens e nós fomos todas com scarpim. Isso mesmo, fomos desfilar com scarpim. Lembro que o comandante pediu pra gente voltar pra trocar, mas ficamos duras iguais estátuas em forma e não trocamos. Ele não pôde fazer nada porque éramos mais de 150 mulheres assim (risos). No final, ele desistiu e nós desfilamos de scarpim. Acabamos todas machucadas do sapato, mas felizes porque era a nossa primeira apresentação pra sociedade. (Maria) 
O primeiro desfile a gente não tinha nem formado, desfilamos lá na Rio Branco, na Tiradentes. Foi a primeira turma desfilando, foi bacana. Expondo a farda, ela era horrível, usava uma saia que embolava nas pernas e tínhamos que usar uma meia fina, não era prática e atrapalhava a andar. (Claudiana)

Nós estávamos no curso e chegou 7 de setembro e tínhamos que marchar, era 7 de setembro no desfile da pátria. Como nós fomos as primeiras, fomos todas escaladas pra desfilar. Nós chegamos no quartel no dia anterior, porque tínhamos que estar às 4h da manhã em forma pra tomar o café e depois partir para a Presidente Vargas às $6 \mathrm{~h}$ da manhã. Todo mundo com uniforme impecável, fazendo avaliação do uniforme e um Comandante olhou pra gente, fez uma avaliação, botou a gente em forma, isso era $4 \mathrm{~h}$ ou $5 \mathrm{~h}$ da manhã, passou a revista, ainda mais porque era o primeiro desfile das mulheres na polícia né. Aí ele olhou o sapato, era aqueles sapatos de boneca, e falou: " Olha, esse sapato, na hora do desfile vai sair do pé". Eu não estou gostando disso, vocês voltem e coloquem o sapato preto de amarrar de cadarço. Ai uma falou:

"Comandante, esse sapato é muito feio, não é feminino, a gente vai parecer homens, a gente já está de cabelo curto". Ai ele falou: "Não quero ponderação, todas as meninas entrem no alojamento e coloquem o sapato de cadarço e voltem a entrar em forma". Aí a gente entrou e uma danada dentro do alojamento falou assim: "Ninguém troca o sapato, ninguém troca o sapato". Depois de 10 minutos, foi esse o tempo que ele deu pra gente trocar de sapato e voltou todo mundo com o sapato de boneca. Ele disse: "Eu falei pra trocar o sapato". (...) Ninguém se mexia. Aí ele falou: "Está bom, podem ir com esse sapato". Os outros comandantes brincaram (risos). Ninguém trocou o sapato. Muitas perderam o sapato no meio do desfile, teve duas que perderam. (...) Poxa, ele mandou a gente trocar o sapato para o que a gente usava nas instruções de tiros, instrução na mata, é aquele sapato de homem fechado tipo um tênis, só que era um sapato, era bem masculino. Parecia sapato de escola, antigamente era de cadarço. Ele foi vencido. Foi a primeira Revolução, isso ninguém fala. (Gisele)

A experiência do desfile remonta um simbolismo profundo do feminismo para as mulheres participantes do evento. Ao narrar o acontecimento, as intérpretes colocaram suas energias fazendo deste um tema carregado de muito sentimento. Percebemos que ao trazer a tona essa lembrança, elas vivenciaram novamente toda alegria que sentiram ao se apresentarem na cidade como as primeiras mulheres a ingressarem na Polícia Militar do Estado do Rio de Janeiro.

\section{CONCLUSÕES}

Nosso objetivo com esta pesquisa foi identificar nas narrativas mnêmicas das entrevistadas possíveis relatos de violências vivenciadas pelas primeiras policiais mulheres após se inserirem na Polícia Militar no Estado do Rio de Janeiro. Focalizamos os tipos de violência física e psicológica, postas em práticas através do assédio moral e sexual, compreendendo que ambos os tipos de violência ainda ocorrem em muitas instituições de forma velada. Este trabalho nos proporcionou compreender melhor a experiência das mulheres no processo de inserção na corporação em questão, porém de forma subjetiva, não linear, identificando as especificidades de como as primeiras integrantes da polícia militar enxergaram sua passagem pela corporação e sem nos prendermos aos fatos históricos já explorados pela literatura utilizada.

Concluímos que as participantes compartilharam experiências de violências, compreendidas como sendo assédio moral e sexual, mas tais práticas aconteceram em um contexto diferente ao que vivemos hoje: sobretudo, porque a primeira turma de formação de mulheres soldados no Rio de Janeiro ocorreu na década de 1980, ou seja, no final da ditadura 
militar. Percebemos que muito do que foi vivido por essas intérpretes dentro da polícia militar, tem relação direta com o conflito instaurado com a quebra de paradigma estabelecido através da inserção delas na corporação. Adentrar o universo militar foi um desafio imposto para essas mulheres, mas também para os que já estavam lá inseridos, ou seja, os PM e oficiais da instituição.

As práticas de assédio moral se deram principalmente no início da experiência das mulheres entrevistadas, quando houve o conflito imediato entre elas e a ordem estabelecida do trabalho, pois já existia um modo de fazer policiamento em diversas atividades e com a entrada da mulher algumas regras passaram a ser revistas. Ofensas, humilhações, expressões verbais com intuito de diminuí-las, foram utilizadas por profissionais homens que faziam parte da instituição. No entanto, é importante salientar que, apesar das experiências com o assédio, as interpretes enfatizaram a proteção que tiveram na corporação logo que entraram como alunas no CFAP. Quanto aos relatos de assédio sexual, também foram, em sua maioria, limitados às insinuações e provocações ocorridas no cotidiano das PMFEM, com exceção de um caso, em que houve de fato violação física (um sargento enfermeiro passou a mão nos seios da PMFEM).

Sobre as estratégias de enfrentamentos utilizadas pelas ex-policiais para suportarem as experiências de violências, identificamos que o silêncio foi posto em prática na maioria dos casos. Isso explica muito sobre o contexto em que elas vivenciaram sua inserção na polícia, pois bater de frente com a cultura já estabelecida na corporação também significava correr o risco de perder o emprego seguro que era almejado por todas elas. Também é preciso sinalizar que tudo aconteceu durante o período da ditadura militar e as leis militares são diferentes das leis civis, fato este mencionado pelas três intérpretes, e isso acarretava medo de elas serem punidas dentro da corporação.

Este estudo revelou a existência da complexidade das experiências subjetivas femininas em lugares culturalmente segregados para o gênero masculino. Portanto, se configura uma pesquisa importante no âmbito psicossocial, pois a partir das narrativas mnêmicas tivemos a oportunidade de conhecer sobre a realidade das primeiras mulheres que ingressaram na polícia militar (PMERJ) do Estado do Rio de Janeiro sob o olhar delas, sem mediações institucionais, e por meio de histórias de vidas.

Por fim, é fundamental destacar a importância de estudos como este para a Psicologia enquanto ciência que estuda as subjetividades, pois a análise de memórias muito pode contribuir para compreensão das práticas coletivas em seus diversos ambientes. Concebemos então esta pesquisa como um produto das construções sociais a partir das lembranças aqui rememoradas pelas intérpretes e, portanto, uma contribuição da Psicologia Social para análise das experiências humanas no tempo.

\section{REFERÊNCIAS}

AVILA, Rosemari Pedrotti de. As consequências do assédio moral no ambiente de trabalho. Dissertação (Mestrado em Direito) - Universidade de Caxias do Sul. Caxias do Sul, p. $158,2008$.

BEZERRA, Claudia de Magalhães; MINAYO, Maria Cecília de Souza; CONSTANTINO, Patrícia. Estresse ocupacional em mulheres policiais. Ciênc. saúde coletiva, Rio de Janeiro 
, v. 18, n. 3, p. 657-666, Mar. 2013. Disponível em: $<$ http://www.scielo.br/scielo.php?script=sci_arttext\&pid=S141381232013000300011\&lng=en\&nrm=iso $>$. Acessado em 22 Out. 2017. http://dx.doi.org/10.1590/S1413-81232013000300011.

BOSI, Ecléa. Memória e Sociedade: Lembrança de velhos. 3 ed. São Paulo: Companhia das letras, 1994.

Editorial, 2003.

O tempo vivo da memória: Ensaios de Psicologia Social. São Paulo: Ateliê

CALAZANS, Márcia Esteves de. Mulheres no policiamento ostensivo e a perspectiva de uma segurança cidadã. São Paulo Perspec., São Paulo , v. 18, n. 1, p. 142-150, Mar. 2004 Disponível em: $\quad<$ http://www.scielo.br/scielo.php?script=sci_arttext\&pid=S0102$88392004000100017 \& \operatorname{lng}=$ en\&nrm=iso $>$. Acessado http://dx.doi.org/10.1590/S0102-88392004000100017.

CODATO, Adriano Nervo. Uma história política da transição brasileira: da ditadura militar à democracia. Rev. Sociol. Polit., Curitiba , n. 25, p. 83-106, Nov. 2005 .

Disponível em: $\quad<$ http://www.scielo.br/scielo.php?script=sci_arttext\&pid=S010444782005000200008\&lng=en\&nrm=iso $>\quad$ Acessado $\quad$ em $1 \overline{8}$ Nov. 2017. http://dx.doi.org/10.1590/S0104-44782005000200008.

GUIMARAES, Liliana Andolpho Magalhães; RIMOLI, Adriana Odalia. "Mobbing" (assédio psicológico) no trabalho: uma síndrome psicossocial multidimensional. Psic.: Teor. e Pesq., Brasília , v. 22, n. 2, p. 183-191, Ago. 2006 . Disponível em: $<$ http://www.scielo.br/scielo.php?script=sci_arttext\&pid=S0102-

37722006000200008\&lng=en\&nrm=iso $>$. Acessado em 15 Ago. 2017. http://dx.doi.org/10.1590/S0102-37722006000200008.

HALBWACHS, Maurice, 1877 - 1945. A memória coletiva. São Paulo: Centauro, 2006.

HELOANI, Roberto. Assédio moral - Um ensaio sobre a expropriação da dignidade no trabalho. ERA -eletrônica, v.3, n.1, Art.10, jan./jun.2004. Disponível em: http://www.scielo.br/pdf/raeel/v3n1/v3n1a12.pdf

LOPES, Emanuel Bruno, BRASIL, Glaucíria Mota. Mulheres na polícia: demarcação dos espaços de comando e relações assimétricas de poder. Fazendo Gênero - Diásporas, Diversidades, Deslocamentos, p. 1-9, Ago. 2010.

MYNAIO, Maria Cecília de Souza (coord.). Missão prevenir e proteger: condições de vida, trabalho e saúde dos policiais militares do Rio de Janeiro. Minayo MCS, Souza ER, Constantino P, coordenadoras. Rio de Janeiro: Editora Fiocruz, 2008. P328

NJAINE, Kathie (Org.). Impactos da violência na saúde. / organizado por Kathie Njaine, Simone Gonçalves de Assis e Patrícia Constantino. - Rio de Janeiro: EAD/ENSP, 2013.

QUEIROZ, Maria Isaura Pereira de. Relatos orais: do "indizível" ao "dizível". In: Experimentos com histórias de vida: Itália-Brasil [S. 1: s.n.], 1988. 
SA, Celso Pereira. Memória, Imaginário e representações sociais. Rio de Janeiro: Museu da República, 2005.

SANTOS, Myrian Sepúlveda dos. Memória coletiva \& teoria social. São Paulo: Amablume, 2003.

SOARES, M. B., MUSUMECI, L. Mulheres Policiais: Presença Feminina na Polícia Militar do Rio de Janeiro. Rio de Janeiro: Civilização Brasileira, 2005.

TINOCO, Rui. História de vida: Um método Qualitativo de investigação. 2004. Disponível em: www.psicologia.com.pt.

VINUTO, Juliana. A amostragem em bola de neve na pesquisa qualitativa: Um debate em aberto. Temáticas, Campinas, 22, (44):203-220, ago/dez, 2014. Disponível em: https://www.ifch.unicamp.br/ojs/index.php/tematicas/article/view/2144/1637.

MT - Ministério do Trabalho, 2013. Cartilha Assédio Moral e Sexual. Disponível em: http://acesso.mte.gov.br/data/files/8A7C812D3CB9D387013CFE571F747A6E/CARTILHAA SSEDIOMORALESEXUAL\%20web.pdf. Acessado em 10/10/2016).

FGV - Fundação Getúlio Vagas, 2015. As mulheres nas instituições militares. Disponível em: http://bibliotecadigital.fgv.br/dspace/bitstream/handle/10438/15255/As_mulheres_nas_institui $\%$ C3\%A7\%C3\%B5es_policiais.pdf?sequence=1\&isAllowed=y. Acessado em 15/06/2016). 